\title{
O gesto fílmico como expressão coletiva da arte cinematográfica
}

\author{
Andréa C. Scansani \\ Doutora; Universidade Federal de Santa Catarina, Florianópolis, SC, Brasil \\ daraca1@gmail.com
}

\section{Resumo}

Este artigo tem por objetivo pensar a realização cinematográfica através da perspectiva coletiva de seus criadores. Na construção desse caminho, partimos da elaboração do que chamamos gesto fílmico como forma de traçar algumas características da natureza do cinema que consideramos relevantes. Esse percurso nos auxilia a desenvolver com maior propriedade as diversas relações entre os agentes presentes em uma filmagem, em que a conjugação de forças humanas e técnicas constitui o próprio ato cinematográfico. As bases teóricas para a concepção do gesto fílmico partem das reflexões de Vilém Flusser sobre o gesto e seguem junto a outros autores que se dedicaram a pensar as especificidades do cinema - como Ricciotto Canudo, Béla Balázs e, mais recentemente, Laura Mulvey-, e que, ao longo de suas obras, apostaram na riqueza semântica do termo como um instrumento de investigação das complexidades intrínsecas à arte cinematográfica. Para examinar a pertinência de nossas colocações, contamos com relatos de nomes importantes da história do cinema como Jean Renoir, Ingmar Bergman, Andrei Tarkovski e Sven Nykvist, que dedicaram parte de suas carreiras à reflexão sobre as particularidades de seu trabalho em equipe. Desse modo, exploramos o caráter coletivo da criação não como um modo de compartilhamento de autoria, mas como elemento fundador da expressão cinematográfica, em que as modulações entre os movimentos humanos e técnicos, entre corpos e máquinas são os pilares do gesto fílmico.

\section{Palavras-chave}

Cinema. Gesto. Vilém Flusser. Jean Renoir. Ingmar Bergman.

\section{Introdução}

Toda imagem cinematográfica, a nosso ver, é dotada de intenção, de certa personalidade, de atributos envolventes [ou repelentes] para além do conteúdo referencial e 
figurativo que preenche nossos olhos através de sua incontornável visibilidade. Ela guarda peculiaridades em sua forma que são, muitas vezes, independentes dos propósitos imediatos de seus autores e que, no entanto, se fazem presentes. Alguns detalhes podem ser acidentais, outros são pensados em suas minúcias. Desse modo, ela porta seus encantos, sua graça ou sua hostilidade, quer tenhamos consciência deles, quer não; algo semelhante àquilo que o senso comum considera um gesto, aquele toque irremediavelmente pessoal, por vezes indescritível, e que transcende o simples ato planejado, como o caminhar de uma pessoa. Há um modo particular de cada corpo se deslocar no espaço. A coordenação e o balanço de ossos e músculos. 0 toque dos pés no chão. A leveza ou o rastejo, a diligência ou o desânimo. A cadência dos braços, a envergadura das pernas. A cada passo o caminhar se constrói, como se o gesto só pudesse se manifestar junto ao tempo, imprimindo sua presença através de seu sutil trajeto, em movimento. Mas como pensar o gesto sendo ele tão instintivo, involuntário e fugaz? Seria ele da mesma natureza da imagem? Se assim indagamos, é porque nos parece genuíno aproximarmos as duas instâncias: imagem e gesto. Não apenas para refletirmos sobre as características únicas de cada manifestação, mas, principalmente, para pensarmos as possibilidades de representação dos gestos através da imagem, algo que é empreendido pelo cinema nas mais variadas formas. Formas essas que também podem ser entendidas como gestos. Uma outra sorte de gesto, um outro caminhar, aquele dado pela convergência de muitos passos. Passos dos atores e dos cenários; da equipe e dos equipamentos; da preparação e da finalização; da montagem e da projeção. Um conjunto de gestos cinematográficos na construção do gesto fílmico, isto é, das imagens [e dos sons] em movimento que constituem o cinema.

No entanto, o franco e imediato encontro da câmera cinematográfica com os corpos filmados não necessariamente satisfaz a intimidade gestual. Uma inevitável dose de imaginação é exigida na expressão em imagens deste ou daquele gesto, desta ou daquela emoção e das tantas expressões de um corpo. Seria possível, então, abrigar em imagens as nuances do gesto? Como oferecer aos olhos, por exemplo, a proporção exata de um caminhar?

Ao atravessar a porta em direção à rua, ele sentiu lágrimas na garganta; mas sabia que aquilo não significava propriamente comoção, e sim, antes, um gradual enfraquecimento dos nervos. Imprimiu deliberadamente uma rapidez e vivacidade a seus passos que não condiziam com seu estado de ânimo. (SCHNITZLER, 2008, p. 89). 
Qualquer gesto banal - como dar alguns passos em direção à rua - pode guardar uma infinidade de camadas não necessariamente visíveis que, no entanto, compõem o quadro do movimento. 0 corpo emocional estará sempre presente, explícito ou não. 0 trecho acima retirado do livro Breve romance de sonho (Traumnovelle, de 1926) de Arthur Schnitzler (2008) e que foi adaptado ao cinema por Stanley Kubrick em sua última obra De olhos bem fechados (Eyes wide shut, de 1999) - nos traz a verdadeira dimensão do desafio enfrentado pelo gesto fílmico. Como dar a ver [e sentir] a densidade dessas poucas linhas? Como transformar em imagens [e sons] o que não se pode observar? Essa, a nosso ver, é a tarefa mais fascinante e árdua do cinema. Parece-nos evidente que não deve haver uma fórmula, nem mesmo pistas pálidas que nos indiquem a direção ideal a ser tomada. Cada cineasta em comunhão com sua equipe, em cada plano filmado, encontrará sua própria maneira de expressar uma lágrima na garganta. No entanto, não nos resta dúvidas de que esse modo único de cada filme, de cada tomada, é resultante da sintonia entre muitos modos individuais. Não apenas os próprios modos presentes nos gestos do corpo do ator, mas principalmente - e é isto que nos interessa -, a transformação desse corpo no processo da realização fílmica. Dessa maneira, faz-se necessário compreender, um pouco mais a fundo, o que entendemos como gesto, um termo certamente inesgotável e do qual nos valemos para estudar o ato cinematográfico, essa construção coletiva de um projeto fílmico.

\section{0 gesto}

A palavra gesto tem ares de curinga. Por vezes, ela ocupa o lugar da ação sem realmente sê-la: o gesto de ler, o gesto de escrever, o gesto de pintar, o gesto de filmar. Por outras, ela parece encarregar-se dos modos, da forma como algo se apresenta: um gesto impensado, um belo gesto, um gesto escorregadio. Uma derivação mais requintada dessa acepção seria pensar o gesto como a maneira pela qual este ou aquele escritor, cineasta, pintor se manifesta. Aí, o gesto estaria relacionado ao estilo, aos procedimentos da criação, à estética. Há ainda algo, nessa rica palavra, que de certo modo abriga o caráter das coisas: um gesto político, um gesto familiar, um gesto técnico. E não poderíamos nos esquivar aqui dos gestos corporais propriamente ditos, como a infinidade de posições específicas das mãos e seus mais variados sentidos: um adeus, um insulto, uma concordância, um pedido de socorro, um beijo. A versatilidade de uso dessa palavra nos diz muito sobre sua natureza. Ela parece ser, ao mesmo tempo, “[...] da ordem do pensamento, do corpo, da imagem, do 
potencial [...]"1 (ROY, 2011, p. 1, tradução nossa). Assim sendo, o livre trânsito entre domínios tão dissemelhantes nos interessa, pois consideramos legítimo olhar para o cinema com o auxílio dessa carta polivalente. Ambos, cinema e gesto, viabilizam um pensamento heterogêneo, uma conjugação de categorias que nem sempre são dispostas num mesmo conjunto.

Ao longo de décadas, a reflexão sobre o gesto aos moldes de uma teoria se faz presente na obra de Vilém Flusser. Ela é elaborada em textos esporádicos, que culminam em seu último livro lançado ainda em vida - Gestos ${ }^{2}$ (Gesten: Versuch einer Phänomenologie, 1991) -, do qual fazem parte análises de gestos específicos como o gesto de escrever, o gesto de amar, o gesto de barbear-se, o gesto de destruir, o gesto de buscar, entre outros. Para além do empenho em esmiuçar os diversos gestos humanos, como no conhecido capítulo 0 gesto de fotografar publicado pela primeira vez no livro A filosofia da caixa preta: ensaios para uma futura filosofia da fotografia ${ }^{3}$ (FLUSSER, 1985), Flusser nos convida a transpor o sentido superficial que possamos depreender do termo ao colocar em perspectiva seu caráter plural. Um dos passos nessa direção se dá ainda em 1975, quando o fundador e editor da revista arTitudes $^{4}$, François Pluchart, propõe ao filósofo a publicação de um artigo intitulado Gesto e sentimentalidade (Geste et sentimentalité), ao que Flusser responde com um curto e inspirado texto. 0 trabalho, escrito originalmente em inglês ${ }^{5}$ sob o título Gesture and sentimentality, é acompanhado de uma versão francesa feita pelo próprio autor. É neste artigo que está, a nosso ver, uma das discussões mais estimulantes sobre a natureza do gesto. E, se expomos aqui a origem bilíngue de sua criação, é porque seu título guarda a chave da complexidade de seu próprio conteúdo. Vejamos como Flusser, ao reescrever o texto em alemão, escolhe a palavra Gestimmtheit para substituir sentimentalidade, um vocábulo de difícil tradução e que é objeto de várias notas de rodapé em todas as obras que

\footnotetext{
${ }^{1}$ No original: "[...] il semble être de l'ordre de la pensée, du corps, de l'image, du potentiel."

2 A versão brasileira foi publicada em 2014 pela Annablume (FLUSSER, 2014b).

${ }^{3}$ Originalmente publicado em alemão sob o título Por uma filosofia da fotografia (Für eine Philosophie der Fotografie), de 1983.

${ }^{4}$ Nota introdutória à edição francesa do livro Les gestes: “François Pluchard, [...] fundador da revista arTitudes, propõe a Vilém Flusser publicar um artigo sobre gesto e sentimentalidade. Vilém Flusser envia a versão em inglês do artigo e sua tradução em 'francês zulu' com uma carta datada de 6 de outubro de 1975. A versão aqui publicada é a reprise do texto co rrigido, tal qual aparece na arTitudes Internacional, n. 25-27, outubro-dezembro de 1975." (FLUSSER, 2014a, p. 248, tradução nossa). No original: "François Pluchart, [...] fondateur de la revue arTitudes, propose à Vilém Flusser de publier un article sur Geste et sentimentalité. Vilém Flusser envoie la version anglaise de l'article et sa traduction e, "français zoulou" avec une lettre datée du 6 octobre 1975. La version ici publiée est la reprise du texte corrigé, tel qu'il a paru dans arTitudes International n. 25-27, octobre-décembre 1975."

5 As traduções variam muito de acordo com as publicações encontradas. Podemos ter em espanhol: Acordamiento [concordância, consonância, afinação]; em inglês: Gesture and sentimentality (original do próprio Flusser], ou Gesture and affect. Já para o livro, a versão alemã é intitulada Gesten: Versuch einer Phänomenologie, publicada pela Bollmann em 1991. Trata-se, portanto, do último livro publicado por Flusser em vida. A versão espanhola é intitulada Los gestos: fenomenología y comunicación, publicada pela Herder em 1994. A versão francesa é intitulada Les gestes, publicada pela D’Arts em 1999. A versão americana é intitulada Gestures.
} 
o citam. Este capítulo, Gesten und Gestimmtheit, ao ser traduzido para outros idiomas, recebe versões das mais variadas e com significados razoavelmente diferentes, como Gesto e afeto, Gesto e afinação, Gesto e concordância, Gesto e consentimento, Gesto e disposiçãao $o^{6}$. A abertura para a possibilidade de múltiplas interpretações faz eco no próprio conceito, que não restringe o pensamento a sentidos conclusivos. 0 próprio gesto intelectual de Flusser, ao ampliar o horizonte semântico do termo, demonstra sua intenção e sua sagacidade. 0 interesse do filósofo parece residir menos em como se define o gesto de modo conclusivo e mais em como o gesto pode deflagrar modos sensíveis de pensar, expandindo a própria noção de pensamento para além da razão, colocando o pensamento numa zona entre fronteiras.

Abordar o gesto através de seu caráter fronteiriço serve-nos como ferramenta para examinar as barreiras necessariamente borradas da cinematografia - essa atividade mestiça [meio técnica, meio arte; meio razão, meio emoção] que transita livremente entre vários campos do saber. Ao longo de seus parágrafos, o filósofo empenha-se em fazer uma fenomenologia do gesto e esboça uma definição, manifestamente inconclusa, com a qual podemos nos aproximar do gesto do [e no] cinema. Para ele, os gestos podem ser compreendidos como movimentos do corpo, e/ou dos instrumentos e ferramentas unidos a este, que expressam uma intenção diferente da razão. Mas o que seria a expressão de uma intenção diferente da razão? 0 caminho percorrido por Flusser para chegar a essa afirmação parte da tentativa de definição do termo "sentimentalidade" [ou sua prima alemã, Gestimmtheit]:

Devo dizer que "sentimentalidade" é a representação simbólica dos sentimentos através dos gestos, e nesse sentido a expressão, a articulação dos sentimentos. Resumindo: devo tentar manter que os sentimentos (o que quer que esta palavra signifique), podem manifestar-se através de uma variedade de movimentos, mas o que expressa e articula "sentimentalidade" é a maneira com a qual são representados.

[...]

E no que diz respeito ao termo "sentimento", eu posso não conhecer o seu significado, mas eu sei que ele significa algo diferente da "razão". E já que eu sei aproximadamente o que significa "razão", esse entendimento negativo do "sentimento" é o suficiente. Portanto, posso dar continuidade

${ }^{6}$ Os três últimos derivados da versão em espanhol: acordamiento. 
na consideração da sentimentalidade como sentimentos gesticulados. ${ }^{7}$ (FLUSSER, 2014a, p. 254-256, tradução nossa).

Se seguirmos as ponderações de Flusser podemos argumentar que a sentimentalidade [essa "representação simbólica dos sentimentos através dos gestos"] é da ordem da forma, da estética. Pois se a expressão dos sentimentos pode se dar através de movimentos dos mais variados, é na maneira com a qual eles se apresentam que reside sua potência em expressar aquilo que não pertence à razão. Aquilo que é compreendido pelos sentidos. Não estaríamos aqui, indiretamente, delineando os elementos constituintes do cinema? Parece-nos natural pensar o cinema como uma expressão emancipada da razão. 0 que não seria nenhuma novidade, pois isso vale para as artes como um todo [como aponta o próprio Flusser]. Porém, para além de seu apartamento da razão, temos a articulação de sentimentos através de sua expressão. Como pensar a expressão dos sentimentos do [e no] cinema? Através de quais dispositivos ela se manifesta? Poderíamos tomar emprestado a inconclusa definição de gesto de Flusser e nela fazer uma breve [talvez leviana] adaptação: o cinema pode ser compreendido como "[...] movimentos do corpo, e/ou dos instrumentos e ferramentas unidos a este, que expressam uma intenção diferente da razão." Assim sendo, as operações dos corpos humanos - obrigatoriamente vinculados a inúmeros artefatos e por eles processados - concebem os gestos cinematográficos. Sua expressão se dará sempre pela articulação entre imagens, movimentos e sons e será fruto de uma infinidade de gestos individuais combinados. Cada gesto [do ator, da câmera, da direção, do cenário, do clima, etc.] na composição de um plano guardaria em si sua natureza: a sentimentalidade, isto é, a potência do afeto, do estado de presença, da disposição, da concordância e da afinação do encontro estético. Essa sentimentalidade, esse modo que prescinde da razão, é expressada já em 1924, por Béla Balázs ${ }^{8}$ em seu $O$ homem visível:

O não falar não significa que não se tenha nada a dizer. Aqueles que não falam podem estar transbordando de emoções que só podem ser expressas

\footnotetext{
7 No original: "[...] je me propose de défendre que la "sentimentalité" est la représentation symbolique des sentiments par les gestes, et qu'elle est, en ce sens, l'expression, l'articulation des sentiments. En bref : j'essaierai de montrer que les sen timents (quoi que ce mot puisse signifier) peuvent se manifester par une variété de mouvements corporels, mais qu'ils s'expriment et s'articulent par une gesticulation appelée "sentimentalité", parce qu'ils sont ainsi représentés. [...] E quant au mot "sentiment", je peux ne pas connaître sa signification, mais je sais qu'il signifie quelque chose différent de 'raison'. Et comme je cannais à peu prés la signification de 'raison", une telle connaissance négative de "sentiment' est suffisante. Je peux donc procéder avec ma considération de la sentimentalité en tant que sentiments gesticulés."

${ }^{8}$ BALÁZS, Béla. Der Sichtbare Mensch, Wien-Leipzig: Deutsch-Österreichischer Verlag, 1924.
} 
através de formas e imagens, gestos e feições. 0 homem da cultura visual usa tais recursos não em substituição às palavras [...]. Ele não pensa em palavras, cujas sílabas desenharia no ar como pontos e traços do código Morse. Os gestos do homem visual não são feitos para transmitir conceitos que possam ser expressos por palavras, mas sim as experiências interiores, emoções não racionais que ficariam ainda sem expressão quando tudo o que pudesse ser dito fosse dito. Tais emoções repousam no nível mais profundo da alma e não podem ser expressas por palavras, que são meros reflexos de conceitos [...]. 0 que aparece na face e na expressão facial é uma experiência espiritual visualizada imediatamente, sem a mediação de palavras. Pensar a imagem para além de sua capacidade de descrever pura e simplesmente um evento pode nos levar a olhar mais de perto as complexidades dos fotogramas gerados pelo mecanismo de uma câmera. (BALÁZS, 1924 apud XAVIER, 1983, p. 78, grifo nosso).

Esta outra forma não conceitual, não racional, com a qual o gesto faz sua morada é, a nosso ver, uma das joias do cinema. E a aproximação desse vocábulo à própria natureza da arte cinematográfica é fato corrente na teoria do cinema. Em seu primeiro texto, publicado ainda na Itália em 1908 sob o título $O$ triunfo do cinematógrafo, Ricciotto Canudo, ao tentar elaborar seus primeiros esboços sobre o que ele mesmo, mais tarde, denominaria como a sétima arte, aponta:

E o gesto rápido, que se afirma com uma precisão de um gigantesco relógio de imagens, exalta o espírito dos espectadores modernos, já habituados a viver com rapidez. A vida "real" é representada de uma maneira suprema, ela é justamente estilizada na rapidez. ${ }^{9}$ (CANUDO, 1995, p. 25, tradução nossa).

A afirmação do gesto cinematográfico como um gigantesco e preciso relógio de imagens parece fazer eco, mais de cem anos depois, no que Laura Mulvey (2015) irá colocar em seu artigo Cinematic Gesture: the Ghost in the Machine, em que ela retoma a análise de imagens nos gestos de Marilyn Monroe em Os homens preferem as loiras (Gentlemen Prefer Blondes, de 1953), de Howard Hawks:

[...] a medialidade dos gestos de Marilyn enaltece o próprio meio cinematográfico como textura material e processual. 0 corpo fílmico na tela também exibe a máquina cinemática em uma fusão do humano e do mecânico. Os gestos de Marilyn desnaturalizam o erótico através do

\footnotetext{
${ }^{9}$ No original: "Et le geste rapide, qui s'affirme avec une précision de monstrueuse horloge à figures, exalte l'esprit des spectateurs modernes, déjà habitués à vivre avec rapidité. La vie 'réelle' est représentée d'une manière suprême, elle est justement 'stylisée' dans la rapidité."
} 
exagero e do excesso [...]. Seus gestos não são simplesmente reapresentados fisicamente, mas são visualmente e tecnologicamente aproveitados e mecanicamente modulados. Em momentos como esse, o cinema se materializa, gesticulando para o seu próprio ser através de sua relação privilegiada com os gestos da figura incorporada a ele. ${ }^{10}$ (MULVEY, 2015, p. 9-10, grifo do autor, tradução nossa)

Entre Canudo (1908), Balázs (1924) e Mulvey (2015), há uma congruência: a fusão entre os gestos da máquina e os gestos humanos [tanto os gestos filmados como os daqueles que filmam] como um modo de expressão que possa dar conta de uma lágrima na garganta, de algo que foge totalmente ao intelecto. No entanto, falta-nos olhar para alguns processos com os quais estes gestos se tornam filme. Visto que podemos pensar o cinema como um conjunto de gestos afinados entre os aspectos humanos e técnicos, investiguemos quais são os agentes desses gestos e o que eles comportam.

\section{0 ato cinematográfico}

Ao acompanharmos relatos de cineastas, muitas vezes nos deparamos com questões que nem sempre se tornam visíveis em suas obras. São detalhes do processo de criação, particularidades das relações que se desenvolvem durante as filmagens, um pormenor de uma cena específica, etc. Apesar do caráter imaterial dessas narrativas, cada autor parece depositar uma grande parcela de responsabilidade sobre a elaboração de seus filmes nessa porção abstrata e, por que não dizer, misteriosa da própria realização coletiva.

Tento fazer esse roteiro de forma a me convencer de que se pode rodá-lo como está, que se pode quase obter um filme seguindo a decupagem plano a plano. Feito isso eu me lanço na produção.

Ocorre então um fenômeno terrível: quando estou na presença dos atores, diante dos cenários, descubro que tudo o que fiz e escrevi não vale nada; descubro que aquela resposta que me parecia cheia de vida não significa mais nada quando é enunciada por um ator que lhe imprime sua própria personalidade; descubro que sou obrigado, na realidade, a conjugar minha

\footnotetext{
10 No original: "[...] the mediality of Marilyn's gestures enhances the medium of cinema itself as process and material texture. The filmic body on display also exhibits the cinematic machine in a fusion of the human and the mechanical. Marilyn's gestures denaturalise the erotic through exaggeration and excess and give a particular edge to her screen appearance. Her gestures are not simply bodily re-presented but visibly technologically harnessed and mechanically modulated. At moments like this, cinema materialises, gesturing to its own being through its privileged relation to the gestures of the figure embodied within it."
} 
própria personalidade com a personalidade do ator (RENOIR, 1990, p. 260, grifo nosso).

A declaração de Jean Renoir mostra com clareza a suavidade, ou melhor, a necessária maleabilidade do ato cinematográfico [pelo menos para ele]. 0 embate entre a ideia no papel e a ideia encarnada apresenta enormes desafios. Cada concepção de um personagem, por exemplo, precisa encontrar um corpo, uma voz, um figurino, um cenário, uma maneira de ser enquadrado, iluminado etc. Para o cineasta, tanto o corpo do ator [acompanhado de suas ideias, de seus trejeitos, de sua formação etc.] quanto sua própria concepção [também escoltada por suas idiossincrasias], ao longo dos ensaios e das filmagens, descobrirão e modelarão os gestos do filme. Cada diretor descobrirá sua própria capacidade de moldar-se [ou não] à realidade imposta por esta ou por aquela obra. É através do conjunto de pequenos encontros humanos [talvez não tão pequenos assim, se pensarmos no encontro entre Jean Renoir e Coco Chanel - quem assina o figurino de A regra do jogo (La règle du jeu, de 1939) que o filme vai sendo forjado. Desse modo, poderíamos pensar o cinema também como um jogo constante entre a ideia e sua concretização, entre a intuição e a razão, entre o planejamento e o improviso ${ }^{11}$. Um jogo cujas regras são aprimoradas a cada movimento dos jogadores envolvidos ou, como sugerido por Renoir, uma conjugação de personalidades, de gestos. Talvez a comunhão entre profissionais não seja verdadeira, nem possível, para todas as produções cinematográficas. Contudo, queremos crer que ela favorece o surgimento das grandes obras.

Os ensaios fluem, reina uma alegria serena. Nossa criatividade dança. Além disso, Anna Asp ${ }^{12}$ nos brindou com uma decoração estimulante e Sven Nykvist posicionou a luz com uma intuição fora do comum que é sua marca genuína [...]. Perguntado sobre o que faz, ele aponta algumas regras básicas e simples [...]. Se por algum motivo se sente inquieto, pressionado ou se está de mau humor, sai tudo errado e ele tem que começar tudo de novo. Em nossa parceria, estamos sempre confiantes e totalmente seguros [...]. Há uma satisfação sensual em trabalhar em íntima cooperação com pessoas fortes, independentes e criativas: atores, assistentes, eletricistas, diretores de produção, encarregados de acessórios, maquiadores, costureiros, todas essas personalidades que povoam o dia a dia e que o fazem suportável (BERGMAN, 2013, p. 77-78).

\footnotetext{
110 que, sem dúvida, é comum às Artes como um todo.

12 Diretora de arte de Fanny \& Alexander, de Ingmar Bergman, de 1982. Fazem parte de sua requintada filmografia, para além de sua parceria com Bergman, obras como O sacrifício, de Andrei Tarkovski, de 1986; As melhores intenções (de Bille August, de 1992) etc.
} 
Em muitos momentos de sua autobiografia, Ingmar Bergman expõe não apenas sua maneira de pensar e criar, mas, principalmente, seu afeto pelos seres com os quais compartilhou a realização de suas obras. Estão presentes em suas páginas atores, produtores, amigos, amores, paisagens, sonhos. A permeabilidade entre obra e vida parece ser regida pela emoção e suas parcerias de trabalho são os alicerces de sua criação. Quanto à direção de fotografia de seus filmes, não é sempre que encontramos exemplos no cinema de associação tão fiel e duradoura como a do cineasta com seu fotógrafo, Sven Nykvist. A conjugação [para estarmos novamente em sintonia com Renoir] destes dois grandes artistas, em mais de vinte títulos e por mais de trinta anos, estabelece um dos capítulos mais ricos da cinematografia mundial. As razões para que haja uma conexão firme e fecunda entre certos indivíduos podem permanecer um mistério; no entanto, há questões sutis que alimentam a criação cinematográfica e para as quais alguns cineastas estão particularmente atentos: "Sven e eu víamos as coisas do mesmo modo, pensávamos as coisas do mesmo modo. Nosso sentimento pela luz era o mesmo. Nós tínhamos os mesmos princípios morais sobre as posições de câmera etc." (NYKVIST, 2000) ${ }^{13}$. Ter ideias semelhantes pode não ser uma prioridade em todas as equipes que se formam, talvez nem seja uma questão relevante para boa parte delas. Entretanto, o que queremos colocar em evidência - a partir da declaração de Bergman - é seu reconhecimento de que a câmera é um instrumento de regência dos preceitos morais dos indivíduos e de que seu posicionamento reflete muito mais do que uma mera opção estética. Ela é, acima de tudo, um dispositivo ético. E como dispositivo ético, a câmera [e, por consequência, seus posicionamentos, seus movimentos, sua exposição etc.] possui a capacidade de materializar os compromissos morais de cada projeto, de cada agrupamento humano designado para esse fim. Talvez aqui esteja uma das chaves para parcerias frutíferas e duradouras e para filmes da envergadura de Fanny \& Alexander, de 1982 [objeto da citação acima]. Para que a criatividade dance com alegria, como dito por Bergman, todos precisam ter a certeza de que estão ouvindo a mesma música silenciosa. De que podem rodopiar cegamente entre os corpos de uma equipe confiável e em sintonia. E de que, mesmo que não tenham as mesmas opiniões, os mesmos desejos estéticos, compartilham de princípios humanos semelhantes. Sendo assim, cada gesto individual e cada pirueta estarão afinados com o gesto final do filme. Não somos ingênuos de pensar que essa é a fórmula de um bom filme, isso não existe. No entanto, temos convicção

\footnotetext{
13 Depoimento de Bergman após a morte de Sven Nykvist presente no documentário Light keeps me company (Ljuset håller mig sällskap, de 2000), dirigido pelo filho do fotógrafo, Carl-Gustav Nykvist.
} 
[e provas] de que os momentos de afinação, concordância, confiança e entrega entre os membros de uma equipe aumentam o potencial criativo individual e coletivo. 0 gesto fílmico é dessa natureza, uma conjugação das potencialidades individuais que atuam em plena sincronia a partir do momento em que a câmera é acionada.

Em qualquer filmagem, os aspectos irremediavelmente humanos estarão presentes e imprimirão a oscilação de sua vulnerabilidade, como narrado por Nykvist em uma entrevista durante as filmagens de Fanny \& Alexander (NYKVIST, 2015). 0 diretor de fotografia - através de uma pequena comparação entre o seu trabalho nos Estados Unidos e na Suécia - nos coloca um novo aspecto a ser pensado dentro da complexa configuração do gesto cinematográfico: a íntima relação entre o corpo humano e sua performance técnica. Em defesa de um horário de trabalho justo, Nykvist comenta como o copião ${ }^{14}$ revela o cansaço de longas horas de filmagem. Pois, a partir de um certo horário - para ele, a partir das quatro horas da tarde -, seus negativos são superexpostos, refletindo na película uma incontornável reação física que faz com que a vista compense seu déficit de sensibilidade gerado pela fadiga ${ }^{15}$. Essa estratégia orgânica de defesa, muito útil para o dia a dia, acaba por influenciar o julgamento do mais experiente diretor de fotografia, mesmo que este esteja equipado com aparelhos precisos de aferição da luz. 0 conjunto máquina-homem, dentro dos domínios da cinematografia, trabalha como se fosse um único corpo. Não apenas a câmera e seu operador - que desfrutam de grande intimidade -, mas todos os elementos diretamente envolvidos na filmagem. Esse agrupamento ocasional, formado por instrumentos técnicos e humanos ["por movimentos do corpo, e/ou dos instrumentos e ferramentas unidos a este e que expressam uma intenção diferente da razão"], tem suas peculiaridades. Um clássico e conhecido exemplo se dá também com Nykvist em sua única parceria com Andrei Tarkovski em seu último filme, O sacrifício (Offret, de 1986):

Não tivemos problemas técnicos ou de qualquer outro tipo durante a filmagem, até um momento, perto do final, quando todos os nossos esforços pareciam prestes a resultar em nada. De repente, na cena em que Alexander põe fogo à casa - uma tomada única com seis minutos e meio de

\footnotetext{
14 Material bruto das filmagens que é analisado diariamente pela equipe.

15 Para além do cansaço muscular dos olhos, temos o esgotamento químico de nossa visão. Tanto os cones quanto os bastonetes possuem substâncias proteicas (iodopsinas e rodopsinas, respectivamente) que absorvem a luz e que são responsáveis pela nossa percepção dos diferentes comprimentos de onda feita através da fototransdução (transformação de energia luminosa em sinais elétricos biologicamente reconhecíveis, que se processa no segmento externo dos cones e bastonetes). Para que o sistema funcione em sua máxima acuidade, os elementos químicos presentes nos sensores precisam ser renovados e isso ocorre com maior eficácia no escuro. Portanto, longas horas de trabalho na dependência da visão podem ocasionar imprecisões fisiológicas não conscientes.
} 
duração [montagem final] - a câmera quebrou. Só fomos perceber isso quando a construção já estava totalmente em chamas, ardendo até o fim diante de nossos olhos. Não pudemos apagar o fogo, nem pudemos fazer uma única tomada; quatro meses de trabalho árduo e dispendioso por nada. Então, numa questão de dias, construiu-se uma nova casa, idêntica à primeira. Parecia um milagre, e isso prova o que as pessoas são capazes de fazer quando movidas pela convicção - e não somente as pessoas, mas os próprios produtores, os super-homens. Ao filmarmos essa cena pela segunda vez ficamos muito apreensivos, até que ambas as câmeras foram desligadas - uma pelo assistente de câmera, a outra pelo profundamente ansioso Sven Nykvist, aquele brilhante mestre da luz. Então relaxamos; quase todos nós chorávamos como crianças, e, quando nos abraçamos, percebi como era íntimo e indissolúvel o laço que unia nossa equipe. (TARKOVSKI, 1990, p. 271).

Imaginemos uma equipe preparada para uma tomada única em longo travelling de uma casa de dois pisos [e de tamanho real] sendo inteiramente consumida em chamas. Como estariam os ânimos dos construtores da casa? Dos responsáveis pelo ateamento do fogo, vindos da Inglaterra especialmente para executar essa tarefa? As chamas começariam por onde havia sido planejado? Seriam elas afoitas ou preguiçosas? Elas cumpririam seu papel dentro dos oito minutos e dez segundos ${ }^{16}$ (CINEPHILIA \& BEYOND, 2017) de negativo? Elas se movimentariam com graça para os olhos da câmera? Estaria o vento a favor da segurança da equipe e dos equipamentos? Como deveria estar o humor de todos que por ali haviam trabalhado por tantos meses? Dos atores que, independentemente de qualquer desconforto ou temor, se ocuparam em executar com primazia suas partes na mise-en-scène? Do maquinista que montou cem metros de trilhos por onde a câmera faria seu vaivém? Do operador do travelling com as inevitáveis acelerações e freadas suavemente sustentadas por seus braços? Do assistente de câmera que carregou o negativo no chassi e ficaria atento às mínimas oscilações da câmera? Do operador que a ligou e que, ao longo do movimento, sentiu seu mecanismo titubear? Não, não podemos subestimar a força de convergência dessas apreensões. Nem em situações de êxito, como na extraordinária segunda chance que se deram, nem no fiasco da primeira investida. Segundo Nykvist, "Aproximadamente no meio da tomada, meu assistente grita: 'Sven, a câmera está perdendo velocidade! Estamos a vinte..., agora a dezesseis quadros por segundo! O que devemos fazer?'."17 (NYKVIST, p. 185, 1997, tradução nossa). Sem que ninguém percebesse [pois

\footnotetext{
16 Tempo descrito por Sven Nykvist em seu livro In Reverence of Light (1997); excerto (p. 181-188) traduzido para o inglês disponível em https://cinephiliabeyond.org/documentary-sven-nykvists-lighting-, último acesso em fevereiro de 2019.

${ }^{17}$ No original: "Approximately half-way through the take, my assistant yells out, 'Sven - the camera is losing speed! We got twenty..., now we're at sixteen frames per second! What shall we do?"
} 
todos estavam absortos pelas labaredas], a câmera - que se recusou a manter seu ritmo de vinte quatro quadros por segundo - foi substituída por outra, que aguardava no meio do trajeto pronta para ser usada em caso de qualquer eventualidade. Mesmo com este diligente planejamento de emergência, a longa e intensa tomada ficou comprometida, fazendo com que não fossem medidos esforços para que o cenário fosse reconstruído e para transformar a tão sonhada cena em realidade. Na segunda tentativa, foram montados dois longos trilhos, um ligeiramente acima do outro. Para cada um deles, uma câmera, um rolo de mil pés de negativo, um operador e um maquinista. Com tal logística, talvez os ânimos [das pessoas e das câmeras] pudessem encontrar algum conforto racional num momento cinematográfico forçosamente emocional ${ }^{18}$.

\section{Considerações finais}

Voltar a atenção para alguns traços nem sempre aparentes dos gestos cinematográficos, como a satisfação de Bergman em "trabalhar em íntima cooperação com pessoas fortes, independentes e criativas"; a constatação de Renoir de que o planejamento de um cineasta só se tornará filme se for ampliado e remodelado por todos os seus agentes; o compartilhamento dos princípios morais implícitos nos posicionamentos de uma câmera ou mesmo uma câmera que parece não ter suportado a apreensão de tantos ânimos voltados para o seu desempenho supostamente maquinal, tudo isso coloca em evidência a natureza necessariamente coletiva e híbrida do cinema. Para além de sua potência em expressar este ou aquele gesto [de uma atriz, do roteiro, da correção de um foco ou de um pôr de sol], o próprio ato cinematográfico é um gesto, ou ainda, uma confluência de gestos técnicos e humanos que sempre trabalharão em conjunto numa espécie de síntese denominada gesto fílmico.

Se insistimos no termo, é para que possamos sempre ter em mente que as "complexidades dos fotogramas gerados pelo mecanismo da câmera" [como dito por Balázs] têm possibilidades abertas e, quiçá, infinitas de expressar "uma intenção diferente da razão" [aqui nas palavras de Flusser]. Um filme está longe de ser apenas uma reprodução [em imagens e sons] de um roteiro. Não que essa definição não seja de certo modo verdadeira,

\footnotetext{
18 Trechos deste momento único do cinema foram registrados por Chris Marker em julho de 1985 e fazem parte de seu filme Um dia na vida de Andrei Arsenevitch (Une journée d'Andrei Arsenevitch, 2000, Icarus Films). Uma delicada homenagem feita ao cineasta russo para a série televisiva francesa Cinéastes de notre temps.
} 
mas as sutilezas do gesto fílmico, coletivo e híbrido, fazem com que esta afirmação se torne menor frente às potencialidades do cinema em expressar aquilo que não pertence à razão ou, em outras palavras, aquilo que é da ordem dos sentidos e que pode ou não estar acompanhado pelo intelecto. Sendo assim, quando enfatizamos a polivalência do gesto como modo de pensar a expressão cinematográfica, não apenas colocamos numa mesma escala de valores as características técnicas, artísticas, afetivas e intelectuais de uma obra, mas, acima de tudo, dedicamo-nos a refletir sobre a rede de conexões que se constrói entre os membros de uma equipe e seus instrumentos ou entre esses membros e a própria concepção [ou concepções] da obra. Este espaço entre os agentes, as ideias e os dispositivos é a morada do gesto, seu ambiente de manifestação e o abrigo deste texto.

\section{Referências}

BALÁZS, Béla. Theory of film: Character and Growth of a New Art. London: Dennis Dobson, 1952.

BERGMAN, Ingmar. Lanterna mágica. São Paulo: Cosacnaify, 2013.

BOYER, Elisabeth. Les gestes au cinéma. L’art du cinéma. Paris, v. 10, mar 1996.

CANUDO, Ricciotto. L'usine aux images. Paris: Nouvelles Éditions Séguier, 1995.

CINEPHILIA \& BEYOND. 'Sätta Ljus': a Documentary about Sven Nykvist's Lighting Process on 'The Sacrifice', 2017.

FLUSSER, Vilém. Geste et sentimentalité. ArTitudes international, Paris, n. 27/29, p. 16-20, 1975.

FLUSSER, Vilém. Filosofia da caixa preta: ensaios para uma futura filosofia da fotografia. São Paulo: Hucitec, 1985.

FLUSSER, Vilém. Les gestes. Bruxelles: Al Dante, 2014a.

FLUSSER, Vilém. Gestos. São Paulo: Annablume, 2014b.

MULVEY, Laura. Cinematic gesture: the ghost in the machine. Journal for Cultural Research, Lancaster, v. 19, n. 1, p. 6-14, 2015.

NYKVIST, Sven. From Tarkovski to Woody Allen. In: NYKVIST, Sven; FORSLUND, Bengst. Vördnad för ljuset (In Reverence of Light). Estocolmo: Albert Bonniers, 1997. p. 181-188. 
Cinema. 2015. Disponível em: https://www.youtube.com/watch?v=t00rVy_U-ek. Acesso em fevereiro 2019.

NYKVIST, Carl-Gustav. Light Keeps me Company (Ljuset håller mig sällskap). Estocolmo: Svensk Filmindustri, 2000.

RENOIR, Jean. Escritos sobre cinema: 1926-1971. Rio de Janeiro: Nova Fronteira, 1990.

ROY, Philippe. Le geste. Appareil, Paris, v. 8, p. 1-2, 2011. Revista online disponível em https://journals.openedition.org/appareil/1243. Acesso em setembro de 2019.

SCHNITZLER, Arthur. Breve romance de sonho. São Paulo: Companhia das Letras, 2008.

TARKOVSKI, Andrei. Esculpir o tempo. São Paulo: Martins Fontes, 1990.

XAVIER, Ismail. A experiência do cinema. Rio de Janeiro: Graal, 1983.

\title{
The filmic gesture as a collective expression of the art of cinema
}

\begin{abstract}
This article explores filmmaking through a collective perspective of its creators. To trace this path, we introduce the conception of what we call filmic gesture as a way of outlining some relevant attributes of the nature of cinema. This route helps us develop the relations between the agents present in a film, where the conjugation of human and technical forces constitutes the cinematographic act. Our theoretical basis on the filmic gesture is constructed from Vilém Flusser's reflections on the term gesture along with other writers who have dedicated their thoughts to the specificities of cinema - like Ricciotto Canudo, Béla Balázs and, more recently, Laura Mulvey. These authors, throughout their works, bet on the semantic richness of the word as an instrument of investigation into the complexities of the art of cinema. In order to examine the pertinence of our proposition, we lean on some important names in the history of cinema such as Jean Renoir, Ingmar Bergman, Andrei Tarkovski and Sven Nykvist, who devoted part of their careers to think over the particularities of their work with their partners. In doing so, we explore the collective character of creation, not as a mode of sharing authorship, but as a founding element of the cinematographic expression, in which the modulations between human and technical moves, between bodies and machines are the cornerstones of the filmic gesture.
\end{abstract}

\section{Keywords}

Cinema. Gesture. Vilém Flusser. Jean Renoir. Ingmar Bergman. 
Recebido em 04/02/2019

Aceito em 10/05/2019 